\title{
LA PRENSA PEDAGÓGICA \\ EN PERSPECTIVA COMPARADA: \\ POTENCIALIDADES, LOGROS Y DESAFÍOS HISTORIOGRÁFICOS
}

\section{The pedagogical press in comparative perspective: potentialities, achievements and historiographic challenges}

\author{
Natalia GARCíA \\ Universidad Nacikonal de Rosario (Argentina) \\ Correo-e: nataliagrs@gmail.com
}

Recibido: 2 de abril de 2020. Enviado a informantes: 8 de abril de 2020 Aceptación definitiva: 28 de julio de 2020

RESUMEN: El presente artículo analiza el campo de la prensa pedagógica comparando el estado de la cuestión en Argentina y en países de América Latina y Europa. Las líneas introductorias ofrecen una breve descripción del proyecto que motiva este trabajo, y una caracterización del singular archivo hemerográfico que conserva los materiales en estudio. Los siguientes apartados examinan las producciones donde esta línea de indagación se halla consolidada (España, Brasil y Portugal), o abriéndose camino (México, Italia, Colombia, Ecuador y algunas regiones de África), puntualizando qué se incluye en esta prensa y qué la distingue; cuáles perspectivas singularizan al área en cuestión y dónde radican sus logros y desafíos académicos. Dado lo anterior, la última sección focalizada en Argentina parte del supuesto de que la prensa pedagógica en tanto campo de estudios autónomo, se halla «inexplorado». No obstante, se identifica una tradición y prácticas de investigación que complejizan el escenario historiográfico.

Palabras Clave: prensa pedagógica; estado de la cuestión; estudios comparados; logros y desafíos; potencialidades.

AвSTRACT: This article discusses the field of the pedagogical press by comparing the state of the issue in Argentina and in Latin American and European countries. 
The introductory lines provide a brief description of the project that motivates this work and a characterization of the unique hemerographic archive that preserves the materials under study. The following sections examine the productions where this line of inquiry is consolidated (Spain, Brazil and Portugal), or making its way (Mexico, Italy, Colombia, Ecuador and some regions of Africa), pointing out what is included in this press and what distinguishes it; which perspectives single out the area in question, and where their academic achievements and challenges lie. Given the above, the last section. focused on Argentina, part of the assumption that the pedagogical press, as a field of autonomous study, is «unexplored». However, a tradition and research practices have been identified that complement the historiographic scenario.

KEY WORDS: pedagogical press; background; comparative studies; achievements and challenges; potentialities.

\section{Introducción: el archivo después del mal de archivo}

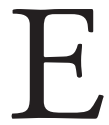

STE TRABAJO NACE de un proyecto de investigación más amplio que, a la luz de las páginas que siguen, conviene describir en primera instancia ofreciendo al lector algunos datos que le permitan comprender por qué nos hemos propuesto analizar el estado de la cuestión de una línea de indagación poco desarrollada en Argentina, tal y como son los estudios en prensa pedagógica. Igualmente, hacer saber que no se pretende aquí un mero ejercicio de erudición comparativa. Ciertamente, las razones finales resultan tan profundas como pragmáticas.

Se trata entonces de una indagación en curso sobre las revistas educativas que circularon en Argentina desde 1950 hasta finales de I970, centrada en aquellas que fueron creadas a instancias del magisterio en el ámbito de la provincia de Santa Fe. Sin adentrarnos en destalles que nos desvíen de este punto introductorio, importa señalar el espacio que custodia dichas publicaciones; esto es, el archivo hemerográfico alojado en la emblemática Biblioteca Popular «Constancio C. Vigil» de la ciudad de Rosario (Santa Fe).

Entre los años I959 y 1977, «Constancio C. Vigil» fue una multifacética asociación civil creada por los vecinos de un barrio obrero ubicado en la zona sur de la ciudad y (auto) financiada por una exitosa rifa que alcanzó a recaudar ingresos millonarios cuando, desde mediados de los '6o, llegó a comercializarse en gran parte del territorio argentino. Para la década del '70, «La Vigil» era una reconocida organización popular de carácter progresista, laico y gratuito conformada por Jardines de infantes, escuela primaria e instituto secundario, universidad popular, servicio bibliotecario, editorial, museo de ciencias naturales, observatorio astronómico, centro recreativo, cultural y deportivo, caja de ayuda mutua, guardería, centro materno infantil y talleres de producción (automotores, herrería, carpintería y construcciones). Naciendo de unas prácticas altruistas del tiempo libre, devino en una experiencia inédita en toda América Latina; una institución de sólido capital financiero y patrimonial dirigida por una Comisión Directiva elegida por el voto mayoritario de la masa de 19.639 asociados y 647 empleados. La obra educativa fue su proyecto más potente con casi 3000 alumnos en sus escuelas. 
El mencionado acervo nació del Programa internacional de canje de la UNES$\mathrm{CO}^{2}$ que «La Vigil» - como mejor se la (re)conoce - implementó desde 1965 hasta que fuera intervenida durante la última dictadura militar (1976-1983)3. Durante esos I2 años, sostuvo relaciones de canje con más de 400 organizaciones nacionales e internacionales de todo el continente americano y países de Europa, Asia, África y Oceanía; con casi todas las universidades y bibliotecas de Argentina, y todo el espectro político-ideológico de América Latina 4 .

A diferencia de la biblioclastía operada sobre la colección de libros que poseías, gran parte del repertorio original resistió la censura dictatorial. Puntualmente, los primeros inventarios realizados en el año 2015 y 2016, arrojaron un total de 83I publicaciones periódicas que abarcan casi todas las áreas del conocimiento y disciplinas especializadas ${ }^{6}$. Asimismo, y siguiendo los parámetros académicos que delimitan el campo según se verá en los siguientes apartados, más de iso ejemplares califican como prensa pedagógica, traducidos en revistas, boletines y periódicos

2 Denominación completa: «Programa internacional de canje entre instituciones culturales no comerciales del mundo» de la UNESCO.

3 Bajo la figura de «intervención normalizadora», el 25 de Febrero de 1977 la institución quedó bajo el control del gobierno de facto provincial, la armada argentina, el ejército, la policía local y civiles profesionales (contadores, escribanos y abogados) especialmente contratados para ejecutar el desguace patrimonial. Ello comenzó en abril del mismo año con el cambió de carátula a «intervención liquidadora», traducida en diversas modalidades y tiempos de destrucción: apropiación ilegal, clausura, quemas, cercenamiento, abandono, expropiación, vandalismo, remates y subastas, robos y saqueos, despidos y cesantías, paralización y asfixia financiera. Asimismo, ocho miembros de la Comisión Directiva fueron ilegalmente secuestrados y alojados en el «Servicio de Informaciones» de la Jefatura de policía de Rosario, transformado en el mayor Centro de Detención y Tortura (CCDyT) de la región. Los mencionados delitos económicos y crímenes contra las personas calificados de «lesa humanidad», al presente se tramitan en los Tribunales Federales de Rosario en la llamada "Causa Feced» que incluye I5s violaciones a los Derechos Humanos, hallándose a las puertas de la sentencia judicial. Tras la recuperación de los bienes e inmuebles que sobrevivieron al saqueo en el año 20I5, la entidad fue señalizada como «Sitio de Memoria del Terrorismo de Estado». Más de veinte socios y socias de la entidad (estudiantes, cooperadores, docentes, y empleados) fueron asesinados o permanecen desaparecidos/as.

4 Desde las actas parlamentarias enviadas por la Biblioteca del Congreso de Washington, los informes sobre crecimiento y desarrollo económico de la CEPAL, a los aportes recibidos de la Biblioteca Nacional de Cuba. Igualmente, desde reputadas instituciones como la Biblioteca Nacional de Francia, la Biblioteca Nacional Lenin de Moscú, el Iberoamerikanisches Institut de Berlín, The Museum of Modern Art de New York, la Unión Panamericana o el Instituto de Cultura Hispánica de Madrid, al exotismo cultural de otras tantas como la Universidad de Abidjan en Costa de Marfil.

5 La destrucción de este acervo alcanzó a unos 85.000 ejemplares (en su mayoría producidos por la editorial de la institución denominada «Editorial Biblioteca») que fueron quemados en los hornos incineradores ubicados en el segundo subsuelo del principal edificio de Biblioteca Vigil. Cuando éstos no dieron a basto, decenas de miles fueron trasladados en camiones del Ejército hasta el cercano Batallón de Inteligencia I2I, ardiendo en grandes fogatas. Otros fueron guillotinados o apropiados clandestinamente por su gran valor comercial. Entretanto, las cajas con publicaciones periódicas despachadas desde todas partes del mundo seguían llegando a la espera del Canje.

6 El fondo hemerográfico fue analizado por las y los trabajadores del servicio bibliotecario, siguiendo los estándares hemerográficos internacionales (ubicación; datos bibliográficos; idioma; temas; contenido y autoridad; presentación; antigüedad y escasez y volumen). 
de Argentina (39\%) o provenientes de América Latina (43\%), Europa (13\%), África (4\%) y EE.UU. (I \%).

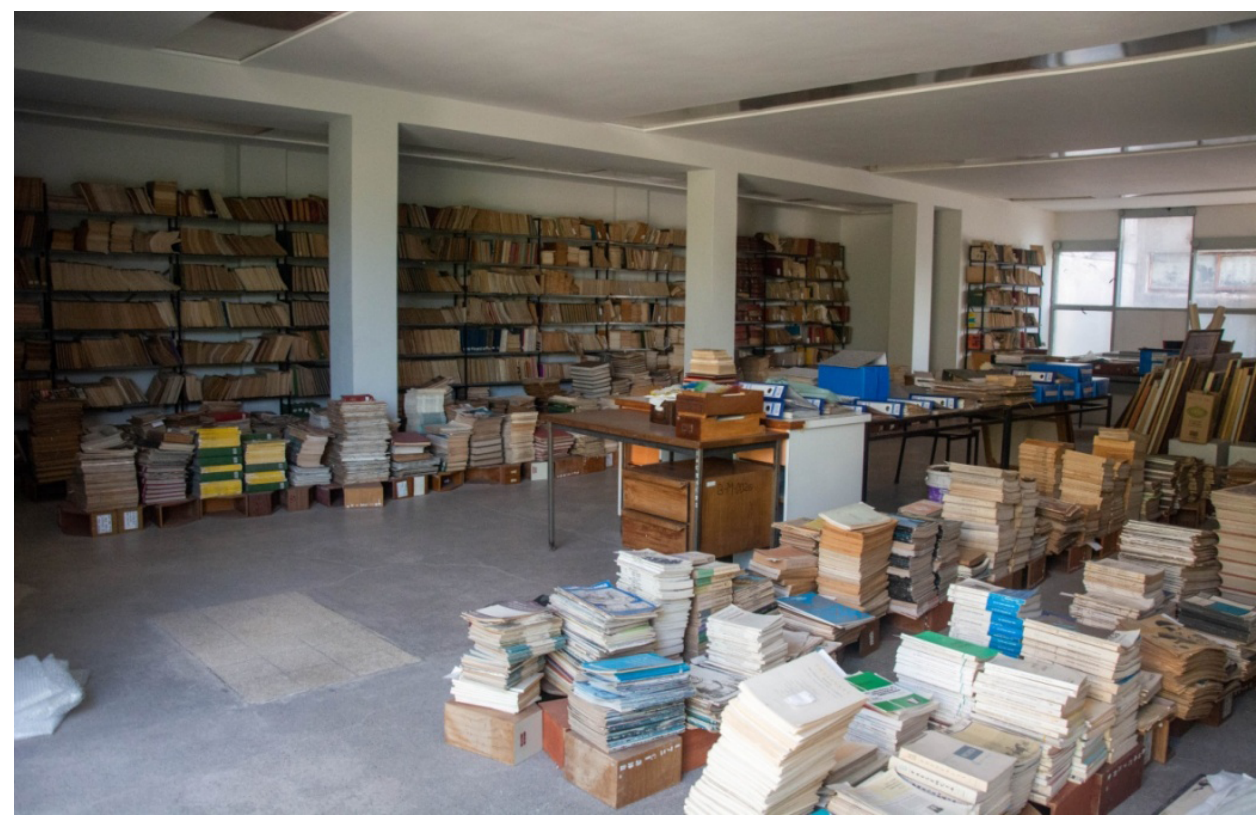

IMAGEN I: depósito de aprox. $120 \mathrm{~m}^{2}$ destinado al archivo hemerográfico, ubicado en la ex sala de lectura (2. ${ }^{\circ}$ piso) de Biblioteca Vigil, año 2020.

Desde ya, tal supervivencia por lejos sorteó la pulsión de muerte y todo lo que entraña el mal de archivo, al decir de J. Derrida (1997)7 dejándonos dolorosas huellas de borramientos y represiones materiales y simbólicas. En términos estrictamente documentales, este fondo es el principal sobreviviente institucional. En tal sentido, y sin ánimos de compararlo con la textura humana, el silencioso depósito encierra los interrogantes culpógenos de una víctima que permanece con vida: ¿por qué no ardió en las mismas llamas que los libros? ¿Qué criterios lógicos así lo decidieron? ¿Solo se trató del absurdo de lo siniestro? ¿Estamos ante un mal radical o ante su banalidad? ?; después de todo, la presencia de algunas revistas también calificadas como "peligrosas» y «subversivas», otrora infligieron dolores de carne y hueso'. Al tiempo que sostenemos que únicamente los perpetradores del terrorismo estatal deben dar respuestas, también podemos dedicarnos

Derrida, J., Mal de archivo. Una impresión freudiana, Madrid, Ed. Trotta, 1997.

8 AREndt, H., Eichmann en Jerusalén, Madrid, De Bolsillo Editorial, 2006.

9 El bibliotecario mayor Raúl Frutos, detenido e interrogado bajo tortura, fue inquirido por dos publicaciones en particular: un libro y una revista. El primero titulado «¿Maestro Pueblo o maestro gendarme?» de María Teresa Nidelcoff, publicado en 1974 en la colección Praxis de Editorial 
a estudiar estos impresos; sus restos y razones, dotándolos nuevamente de su potencia patrimonial bajo las claves historiográficas de la prensa pedagógica. A nuestro entender, ello tendría el doble mérito de aportar nuevos conocimientos académicos y constituirse en un acto de reparación de los delitos cometidos. Allí descansa parte importante de la materia prima con la cual se reconstruye la memoria y la historia educativa ${ }^{10}$, comenzando por la elemental tarea de evaluar las deudas, logros y desafíos del campo en el cual pretendemos inscribir sus resultados.

\section{El estudio de la prensa pedagógica en el ámbito internacional: un campo consolidado y en expansión}

La literatura especializada establece dos condiciones para delimitar qué materiales pueden considerarse ejemplares de prensa pedagógica: la periodicidad de las publicaciones y la orientación de su contenido. Es decir, que se cumpla una secuencia temporal de los números impresos (semanal, quincenal, mensual, etc.) sin desmedro de su breve o extensa vida editorial, y que «mantenga un criterio de atención y estudio expresamente interesado en asuntos que afectan a los procesos de la educación, dentro de la institución escolar o en otras diferentes, pero también educativas y formativas $»^{\text {II }}$. Como a priori puede observarse, un requisito resulta preciso y acotado, y otro habilita un universo amplio, heterogéneo y de márgenes difusos; «(...) un mar de posibles publicaciones educativas» ${ }^{12}$.

Asimismo, se abren dos perspectivas que demarcan la especialización del campo: por un lado, la prensa como fuente documental; por el otro, como un objeto «autónomo» al decir de A. Nóvoa (1997) ${ }^{13}$ o "patrimonio» para algunos autores españoles. La primera remite a la simple utilización de los impresos para recabar información específica del pasado educativo. La segunda le concede una capacidad hermenéutica suficiente y exclusiva para edificar una línea de investigación.

Biblioteca. La revista era la afamada «Bohemia» de Cuba, uno de los tantos ejemplares de la colección que llegaba desde «Casa de las Américas».

ro Vale como ejemplo mencionar que se ha comenzado el estudio de una revista hallada en dicho acervo denominada: «Hacer. Publicación mensual para maestros». Originaria de Rosario, fue creada en 1967 por un grupo de profesores, pedagogos y maestros que, a la sazón o en los años siguientes, fueron destacados referentes de las vertientes progresistas del campo pedagógico y cultural, algunos de ellos de proyección nacional e internacional. La colección - dada por perdida - se extendió en is números hasta el año i970.

" Hernández Díaz, J. M., (Ed.), Prensa pedagógica y patrimonio histórico educativo. Contribuciones desde la Europa mediterránea e Iberoamérica, Salamanca, Ediciones Universidad de Salamanca, 2013, p. I6.

https://www.researchgate.net/publication/257458892_Prensa_Pedagogica_y_Patrimonio_Historico_Educativo_Contribuciones_desde_la_Europa_Mediterranea_e_Iberoamericana

${ }_{12}$ Ibidem.

${ }_{13}$ Nóvoa, A., A imprensa de Educação e Ensino, en Catani, D. y Bastos, M. E. (Org.): Educação em Revista. Imprensa Periódica e História da Educação, São Paulo, Escrituras, 1997, pp. II-32. 
Siguiendo los criterios mencionados, la evaluación del estado de la cuestión en el ámbito internacional, deja pocas dudas respecto de la gravitante productividad española, ya fuere en términos cualitativos como cuantitativos. Tras un primer relevamiento, se registran más de ioo publicaciones enteramente sustentadas en periódicos, revistas y/o boletines seleccionados para el análisis de diversos objetos y problemáticas.

La temprana emergencia hispánica se sigue en los libros y capítulos de C. Alcázar Molina, J. M. Vázquez, L. Sastre, M. Jerez, C. Lozano Seijas, A. Mayol, M. Lázaro Lorente y L. Esteban Mateo ${ }^{14}$, a la sazón interesados en la infancia, el magisterio, la universidad y/o la promoción de experiencias renovadoras. Lo dicho constituyó la agenda temática inaugural de un campo todavía sin nombre. Hoy día, los mencionados autores y sus obras se definen como «(...) Instrumentos imprescindibles para el estudio de la prensa pedagógica en España»" de avanzadilla para nuestro tema» ${ }^{16}$.

Hacia los años '8o, las investigaciones se triplicaron en un talante que perdura. Nos referimos a los abordajes locales y/o regionales, reiterándose los casos de Canarias, Cataluña, Asturias, el País Vasco, Castilla y León, Castilla-La Mancha, Galicia, Navarra y Madrid. Interpretamos que ello deviene de la propia organización del Estado español, extendiéndose - en consecuencia - a los respectivos gobiernos de la educación, sus instituciones, organizaciones, agentes, redes, actores y, claro está, al numen de estas singulares fuentes. Dicho en otros términos, el campo de la prensa pedagógica en España parece moldearse bajo el particularismo de sus comunidades autónomas.

Para esta década también, se registran las primeras tesis de grado y postgra$\mathrm{do}^{17}$, y surgen valiosas catalogaciones de tipo censal ${ }^{18}$ que, a nuestro entender, se erigen como la empresa historiográfica más desafiante e imperiosa. No obstante,

14 Alcázar MolinA, C., Historia de una revista. "Filosofía y Letras", Madrid, Universidad de Madrid, 1953; VÁzQuez, J. M., La prensa infantil en España, Madrid, Doncel, 1963; SASTRe, L., El Magisterio Español. Un siglo de periodismo (I867-1967), Madrid, Edit. Magisterio Español, I967; JerEZ, M., La Revista Nacional de Educación, 194I-1945, en AA.VV.: Las fuentes ideológicas de un régimen. Zaragoza, Universidad de Zaragoza, 1978; LozANo SEIJAS, C., La prensa pedagógica durante la II República, Perspectivas Pedagógicas, 4I (1978), pp. 193-203; MAYol, A., Boletín de la Escuela Moderna, Barcelona, Tusquets, 1978; LÁzAro Lorente, L. M., Publicaciones pedagógicas del legado Navarro Cabanes de la Hemeroteca Municipal de Valencia, III Jornades d'Historia de l'educació als Paisos Catalans, Girona, pp. 9-Io. 1979; Esteban Mateo, L., Boletín de la Institución Libre de Enseñanza. Nómina bibliográfica (I877-I936), Valencia, Universidad de Valencia, I979.

is Rebordinos Hernando, F. J., Recensiones, Revista Historia de la Educación, Salamanca, Universidad de Salamanca, 33 (20I4), p. 440. https://revistas.usal.es/index.php/0212-0267/article/ view/12716/13009

16 Op. cit., Hernández Díaz, J. M., Prensa pedagógica y patrimonio..., 2013, p. I8.

${ }_{17}$ Bartolomé Crespo, D., Revisión del concepto de prensa infantil juvenil, Madrid, UCM, 1983; Muñoz Codina, M. R., La prensa pedagógica barcelonesa en el siglo XIX, I984.

i8 Checa Godoy, A., Aportaciones para un censo de la prensa pedagógica en España, Historia de la Educación, 5, (1986-1990), pp. 502-19, pp. 417-38, pp. 253-8I, pp. 343-75, pp. 325-46; LEÓN, E. y López MARTín, R., La prensa pedagógica en su devenir histórico, Revista española de pedagogía, La Rioja, I92 (1992). 
los auspiciosos repertorios analíticos no prosiguieron en una proyección constante ni suficiente. Al decir de J. M. Hernández Díaz «(...) todavía echamos en falta en España instrumentos de localización y descripción (...) semejantes a los ya existentes desde hace algunos años en diferentes países de nuestro entorno ${ }^{19}$.

Sus palabras bien pueden aludir a los extraordinarios volúmenes dirigidos por el belga M. De Vroede ${ }^{20}$, a las notables faenas de P. Caspard en Francia ${ }^{21}$ y ulteriores realizadas junto a $\mathrm{P}$. Karudis ${ }^{22}$; especialmente, a la obra de A. Nóvoa en Portugal ${ }^{23}$ por cuanto trasunta la inexpresiva tarea de inventario, constituyéndose en un repertorio analítico de meridiana claridad teórico-metodológica para otros investigadores donde esta línea se halla igualmente consolidada, tal y como Brasil, o abriéndose camino como sucede en México, Italia, Colombia, Ecuador y algunas regiones de África.

Al respecto, y bajo la consideración de los obstáculos que nos presenta el acceso a bibliografía gestada fuera de Argentina, sintetizamos los datos recabados en el siguiente cuadro:

CuAdro I: estudios publicados sobre prensa pedagógica fuera de Argentina por años y países.

\begin{tabular}{|c|c|c|c|c|c|c|c|c|c|}
\hline Años & España & Brasil & Francia & Portugal & Italia & México & Colombia & Ecuador & África \\
\hline $\begin{array}{l}1980 \\
1990\end{array}$ & 23 & I & 3 & - & - & - & - & - & - \\
\hline $\begin{array}{l}\text { I99I } \\
2000 \\
\end{array}$ & I5 & 4 & I & 3 & I & - & - & - & - \\
\hline $\begin{array}{l}2001 \\
2010\end{array}$ & IO & 8 & - & 2 & I & I & - & - & - \\
\hline $2 \mathrm{OII}$ & I & - & - & - & - & - & - & - & - \\
\hline $2 \mathrm{OI} 2$ & 2 & - & - & - & - & - & - & - & - \\
\hline 2013 & 23 & 9 & I & 5 & 2 & - & - & - & I \\
\hline 2014 & I & - & - & - & - & - & - & - & - \\
\hline 2015 & 28 & 44 & I & 3 & 2 & I & 2 & & 7 \\
\hline
\end{tabular}

19 Op. cit, Hernández Díaz, J. M., Prensa pedagógica y patrimonio..., 20I3, p. 25.

20 De Vroede, M., Bijdragen tot de geschiiedenis van het pedagogisch leven in Belgie in tde Igde en zoste eeuw. De periodieken, Gent, Université Catholique ded Louvain, 1973-1987, 6 vols.

${ }_{21}$ Caspard, P., La presse d'éducation et d'enseignement (XVIIIé siècle-I940). Repertoire analitique. Paris, Institut National de la Recherche Pedagogique, 1981, 1984, 1986,1991, 4 vols.

22 Caspard, P. y Karudis, P., La pressed'éducation et d'enseignement. I94I-I9go. Répertoire analytique, Paris, Institut National de la Recherche Pedagogique 2000, 2003, 2005.

${ }_{23}$ Nóvoa, A., A imprensa de educação e de ensino. Repertório Analítico (séculos XIX e XX), Lisboa, Instituto de Inovação Educacional, i993; NóvoA, A., Bandeira, F., Paulo, J. C. y Teixeira, V., A imprensa de educação e ensino: Concepção e organização do repertório portugués, en, D. CATANI y Bastos, M. E. (orgs.), Educação em Revista, São Paulo, Escrituras, 2002, p. II-3I. 


\begin{tabular}{ccccccccccc}
\hline 2016 & - & I & - & - & - & I & - & - & - \\
\hline 2017 & - & - & - & - & - & - & - & - & - \\
\hline 2018 & 25 & 43 & - & I9 & I0 & IO & 3 & I & II \\
\hline 2019 & - & - & - & - & - & - & - & - & - \\
\hline 2020 & - & I & - & - & - & - & - & - & - \\
\hline
\end{tabular}

Fuente: elaboración propia.

Desde los ámbitos señalados, se abren gradientes de productividad que redundan en los siguientes porcentajes:

GrÁFICO I: estudios publicados sobre prensa pedagógica fuera de Argentina. Distribución porcentajes por países.

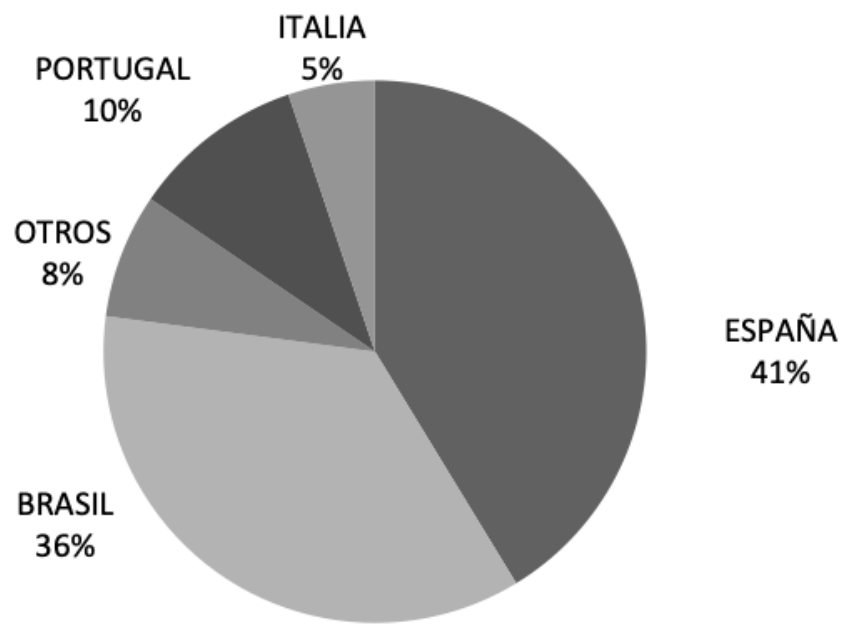

Fuente: elaboración propia.

Brasil se posiciona entonces en un lugar igualmente relevante, destacándose - por su influencia - los estudios de M. E. Bastos ${ }^{24}$, incluidos aquellos capítulos

${ }_{24}$ Bastos, M. H., As revistas pedagógicas e a atualização do professor: A Revista do Ensino do Rio Grande do Sul (195I-1992), en CATANI, D. y Bastos, M.H.C. (Org.). Educação em Revista. A Imprensa periódica e a História da Educação, São Paulo: Escrituras, 1997, pp. 47-76; Espelho de papel: imprensa e história da educação, en Araujo, J. y GatTi Jr., (Org.), Novas abordagens em história da educação: imprensa e instituições escolares, Uberlândia, EDUFU, 2002, pp. I5I-174; Pesquisa em história da educação em revista, en Schelbauer, A., Lombardi, J. y MAchado, M. (Orgs.) Educação em debate: perspectivas, abordagens e historiografía, Maringa, UEM, pp. 99-128, 2006a; BASTOS, M. E., La prensa de educación y enseñanza: observatorio de la formación de docentes y alumnos (Brasil, 
que la autora escribe junto a D. Catani ${ }^{25}$ por un lado, y E. Lemos ${ }^{26}$ por el otro. En su conjunto, los aportes se reúnen en compilaciones que abordan a la prensa pedagógica como un «objeto histórico-educacional» en diversos tratamientos metodológicos.

En las restantes geografías académicas, el escenario cambia significativamente más allá de sus comparativas desproporciones: leves o pronunciadas. En la mayoría de estos casos, las palabras de la mexicana I. Moreno Gutiérrez resultan un descriptor oportuno; esto es: «Los estudios históricos sobre la prensa pedagógica son un campo virgen y fértil que espera la llegada de los historiadores ${ }^{27}$. Sobre los trabajos que provienen de Âfrica (Gabón, Guinea Ecuatorial y Mozambique), es dable aclarar que, salvo contadas excepciones, no se adentran en la historia educativa sino que utilizan este tipo de prensa para el análisis de una agenda contemporánea ligada a las problemáticas de género, racismo y estrategias didácticas para la enseñanza del español como lengua extranjera.

En cuanto al ritmo de la productividad, los datos recabados muestran una significativa concentración de publicaciones durante el último decenio, dibujando una curva ascendente que satura en los años 2013, 2015 y 2018. Gráficamente:

GRÁfICO II: ritmo de las publicaciones sobre prensa pedagógica fuera de Argentina.

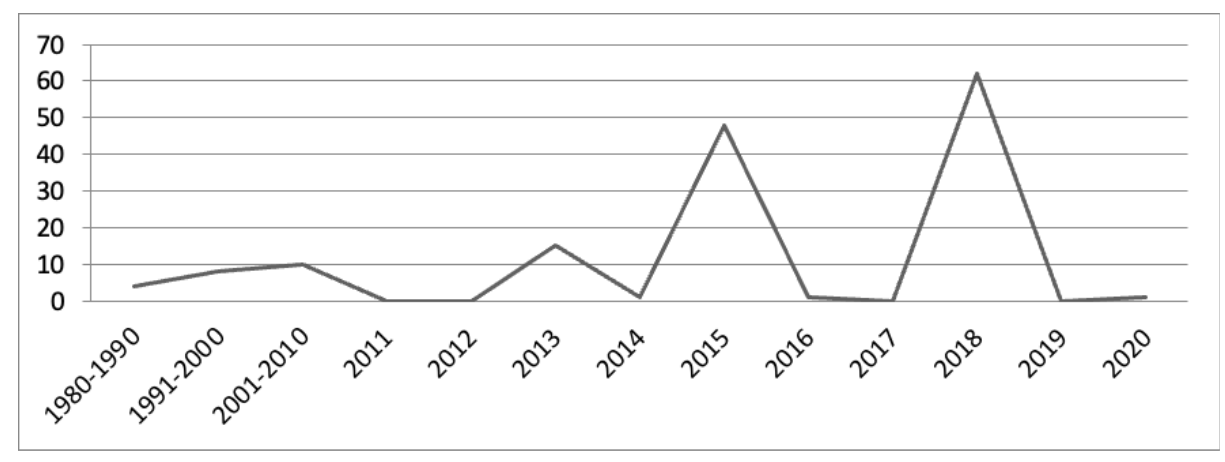

Fuente: elaboración propia.

1950-1980), La Plata, Archivos de Ciencias de la Educación, Io (2016). https://www.archivosdeciencias.fahce.unlp.edu.ar/article/view/Archivoseoo3

${ }_{25}$ Catani, D. B. y Bastos, M. H., Educação em revista. A imprensa periódica e a história da educação, São Paulo, Escrituras Editora, 1997.

${ }_{26}$ Bastos, M.H.C. y Lemos, E. A., «Uma iconografia da cultura escolar: a Revista do Ensino/ RS (19511978)». En Araújo, J., y Schelbauer, A. (Org.), A imprensa como objeto histórico-educacional: metodologias e abordagens, Campinas, Autores Associados, 2006.

${ }_{27}$ Moreno Gutiérrez, I., La prensa pedagógica en el siglo XiX, en Galván L. (Coord.), Diccionario de Historia de la Educación, México DF, CIESAS, CONACYT, UNAM, 2002, p. 2. http:// biblioweb.tic.unam.mx/diccionario/htm/articulos/sec_23.htm 
Así, se registran 4I nuevos estudios en el año 2013, más del doble (89) en 20I5, y otros I22 tres años después. Es decir, en apenas un quinquenio, el campo aumenta un $300 \%$ su producción general. En gran medida, ello se debe a la realización de las «Jornadas Internacionales de Estudio sobre Prensa Pedagógica y Patrimonio Histórico Educativo", organizadas por la Universidad de Salamanca en tres ediciones consecutivas; a saber: una primera jornada denominada «Contribuciones desde la Europa mediterránea e Iberoamérica» (2013), las segundas orientadas a «La prensa de los escolares y estudiantes» (2015), y las terceras sobre «La prensa pedagógica de los profesores» (2018) ${ }^{28}$. Se interpreta que estos eventos académicos dieron paso a una etapa fecunda propia de la sinergia de una comunidad internacional. Conviene entonces detenernos en ella para observar y evaluar sus principales intereses y abordajes.

\section{Lo pasado $\mathrm{p}(\mathrm{r})$ ensado: problemas, objetos y perspectivas}

La valoración de las aludidas jornadas salmantinas cobra cabal sentido en sus debates historiográficos y objetos tratados. Al respecto, las pesquisas se adentran en la prensa de las asociaciones de profesores per se, ligados a intereses laborales y/o gremiales o a movimientos de renovación pedagógica. Del mismo modo, analizan el papel de las elites intelectuales, las plumas de respetables pedagogos con posiciones dominantes en el gobierno de la educación, docentes de corte rupturista que orbitaron espacios alternativos o ignotas «maestras giornalistas», al decir de A. Cagnolati ${ }^{29}$.

La tradición historiográfica de rastrear el pasado educativo desde los boletines gubernamentales cuenta con numerosos trabajos, en tanto otros se abocan a periódicos y revistas especialmente diseñados como soporte didáctico, sin por ello ingresar en el ámbito de la manualística. También se estudian materiales abocados a la divulgación de las ciencias o prensa científica y a las artes o educación artística.

Tal variopinto universo conlleva similar heterogeneidad de actores y problemáticas quedando, en primera instancia, «(...) ese mundo de escritos que tal vez leyeron los maestros», según lo identifica la ya citada investigadora I. Moreno Gutiérrez $^{30}$. Le siguen los estudiantes y los niños, para así leer las representaciones

28 Los trabajos fueron publicados en: Op. cit., Hernández Díaz, J. M., Prensa pedagógica y patrimonio..., 20I3; Hernández Díaz, J. M., (Ed.), (2013); Hernández Díaz, J. M. (Ed.), Prensa pedagógica, mujeres, niños, sectores populares y otros fines educativos, Salamanca, Ediciones Universidad de Salamanca, 20I5; Hernández Díaz, J. M., La prensa pedagógica de los profesores, Salamanca, Ediciones Universidad de Salamanca, 2018.

29 Cagnolatti, A. La stampa pedagogica per le donne in Italia (I86I-1900). Esempi, temi e finalità, en Hernández Díaz, J. M. (Ed.), Prensa pedagógica y patrimonio histórico educativo. Contribuciones desde la Europa mediterránea e Iberoamérica, Salamanca, Ediciones Universidad de Salamanca, 2013, pp. 33-52.

30 Op. cit, Moreno Gutiérrez, I., La prensa pedagógica en el siglo XIX..., 2002, p. 23. 
juveniles o la carnadura de las infancias (desamparadas o cobijadas) al calor de la historia; respectivamente. En similares orillas se examina la situación de las mujeres, las voces y acciones de los sectores populares o los grupos que traccionaron procesos emancipatorios.

En el horizonte mediano, se intentan medir los impactos de las transformaciones sociopolíticas en la cultura escolar, los tempos y condiciones de posibilidad para la conformación de redes socio-profesionales, sus posturas y/o pronunciamientos ante las políticas educativas y las querellas entre los argumentos confesionales y laicos en los albores de un sistema educativo o en momentos de inflexión. Por lo mismo, se exploran doctrinas y adoctrinamientos, militancias e idearios político-partidos y subjetividades prendidas en los discursos de época. A propósito, puede decirse que la prensa pedagógica comporta una estructura y textura que le sienta muy bien a los análisis discursivos, con sus juegos de enunciación y signos de debate presentes en las usuales secciones de intercambios o cartas de lectores.

Como resulta esperable, la presencia de las corrientes pedagógicas y de otras disciplinas del saber, importan especialmente a los investigadores para calibrar sus decisivas y/o transitorias influencias en la conformación del aparato educativo, abriendo preguntas sobre el acceso de la ciudadanía a los conocimientos en cada contexto, los consumos culturales y las propuestas y métodos de enseñanza. En este punto, algunos autores se muestran muy entusiastas respecto de la posibilidad de capturar el complejo asunto de la cotidianeidad escolar cuasi como una «guía práctica» por cuanto muestra, a criterio de D. Catani y M. E. Bastos, «(...) el grado de aceptación de programas e instrucciones oficiales, de la ideología oficial y del cuerpo docente, de las fuerzas de cambio y continuidad que representa, de las contradicciones del discurso» ${ }^{31}$. En igual sentido, A. Nóvoa opina que «(...) es difícil imaginar un medio más útil para comprender las relaciones entre teoría y práctica, entre proyectos y las realidades, entre tradición e innovación» ${ }^{32}$.

Cuando la publicación seleccionada es generosa en información y/o se recurre al cruce de otras fuentes documentales, visuales y/o testimoniales, los estudios se enriquecen incorporando las dinámicas que se activan tras la aparición de los impresos. En estos casos, el escenario cobra vitalidad como en un film de cambiantes escenas donde entran y salen los autores (editores, redactores, colaboradores), los intermediarios (asociaciones, libreros, comerciantes) y los posibles lectorados, componiendo una comprensión más aguda sobre los núcleos y agentes de producción, circulación, propagación y sus recepciones en terreno.

Finalmente, en cuanto a las tendencias o preferencias sobre los periodos históricos abordados, es claro que los pasados nacionales traccionan e incluso saturan algunas temáticas y coyunturas. Vale como ejemplo el caso español, bien interesado en las experiencias educativas inscriptas en los años de la Segunda República,

${ }^{31}$ Op. cit, Catani, D. B. y Bastos, M. H., Educação em revista..., I997, p. 23.

32 Nóvoa, A., Os professores na virada do milênio: do excesso dos discursos à pobreza das práticas, Educação e Pesquisa, São Paulo, 25 (I999), p. 3I. https://doi.org/I0.1590/Si517-97021999000I00002. 
el devenir de la emblemática «Institución Libre de Enseñanza» y/o las variantes de la Escuela Moderna; entre otros. Como puede verse en los siguientes gráficos, la situación se modifica según las historias regionales.

GRÁfICO III: Distribución de los periodos en estudios sobre prensa pedagógica en España.

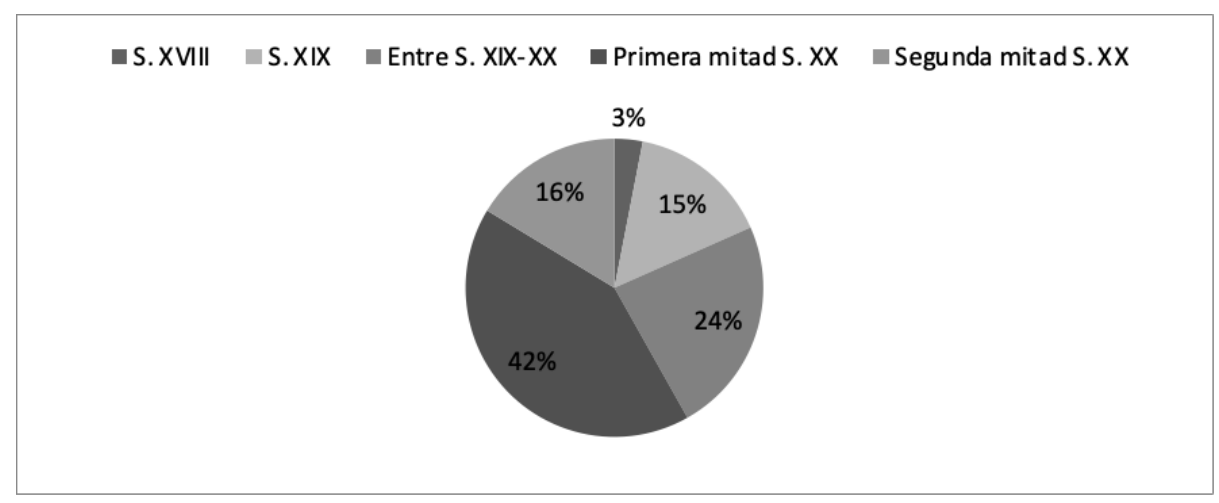

Fuente: elaboración propia.

GRÁfICO IV: Distribución de los periodos en estudios obre prensa pedagógica en Brasil.

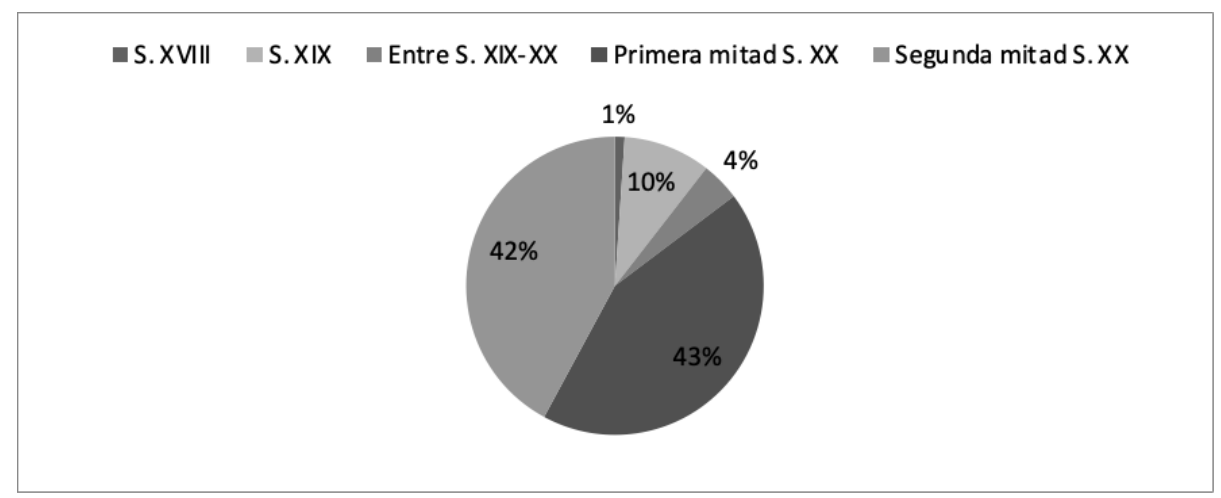

Fuente: elaboración propia. 
GráfICO V: Distribución de los periodos en estudios sobre prensa pedagógica en Portugal, Francia, Italia, México y Colombia.

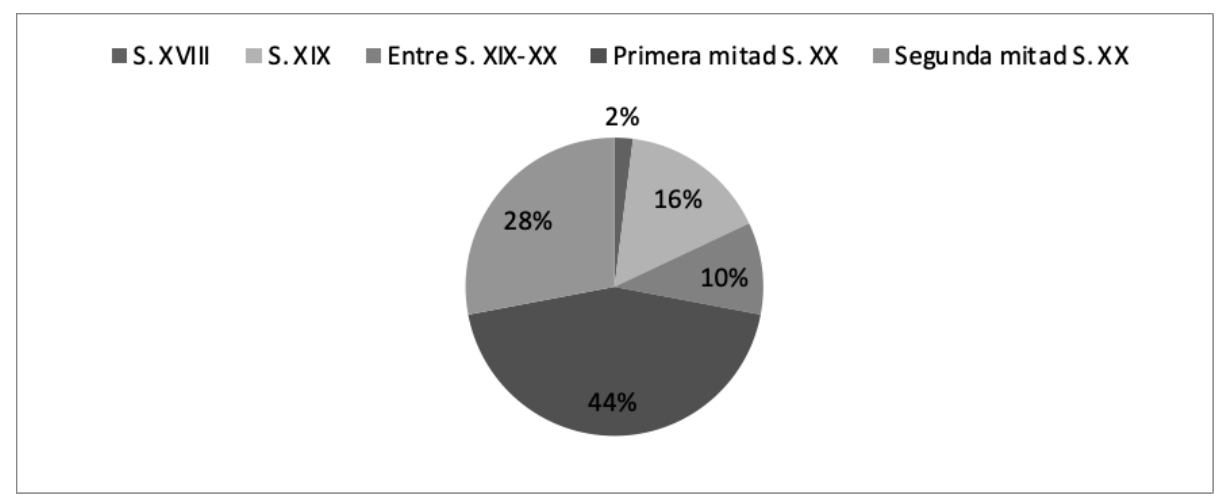

Fuente: elaboración propia.

\section{Prensa pedagógica en Argentina: un tesoro inexplorado y una literatura gris}

Para trazar un diagnóstico y pronóstico del estado del arte en Argentina, partimos de dos premisas que se asemejan a lo informado en países que recientemente han sumado esta línea de investigación a su quehacer académico. Esto es, la prensa pedagógica es un elemento protagónico del pasado educacional, no obstante, en palabras de S. Finocchio, se trata de un «tesoro inexplorado» ${ }^{33}$. Así, la bibliografía bajo análisis, se ordena desde las preguntas que dispara tal aseveración: ¿Qué riquezas históricas contiene dicho tesoro? ¿En qué sentidos y aspectos se halla inexplorado? ¿Hasta dónde es válida dicha afirmación en términos historiográficos y especialmente heurísticos?

Claro que, la partición de perspectivas descripta paginas atrás, por lejos resulta un dato accesorio para antes establecer qué se incluye y qué se excluye como antecedentes. Nuevamente, si por prensa pedagógica se entiende la labor hemerográfica puesta a reconstruir un pasado educativo o problemáticas contemporáneas enteramente ajenas al material en cuestión, se abre un continente inabordable en la historia educativa argentina. Si en cambio nos cernimos a indagaciones que explícitamente abrevan a ella como objeto autónomo, la cuestión se reduce a

33 Finocchio, S., Un tesoro inexplorado: los periódicos escolares en la Argentina, Brasil, História da Educação, Rio Grande do Sul, 17 (2013a), pp. 27-54. https://doi.org/Io.159o/S223634592013000200003 . 
un puñado de textos que tienen por referencia principal a los estudios individuales y colectivos de S. Finocchio publicados en Argentina y España ${ }^{34}$.

No obstante, también advertimos la presencia de una «literatura gris» que desnuda lo (siempre) provisional de las categorías apriorísticas. Esto es, pesquisas que no se declaran en esta línea pero sustentan sus estudios en publicaciones periódicas, y lo hacen bajo un tratamiento teórico y abordaje metodológico que acaban por situarlas a las puertas de este campo. Por caso, son textos que dedican extensas páginas a la descripción del material en cuestión (mayormente revistas), señalando sus orígenes, desarrollo temporal y espacial, objetivos, actores, grupos y redes constitutivos, secciones, etc., e incluyendo rupturas y continuidades de su propia vida editorial o en relación a un escenario mayor. Si se quiere, estamos ante un grupo de antecedentes «tácitos», por cuanto no se inscriben en los dominios del lenguaje disciplinar pero sí en su régimen epistémico.

Desde tales coordenadas, podemos decir que los primeros trabajos se publican en la década del '9o. Dos de ellos se ocupan de la emblemática revista infantil «Billiken», creada en igI9 con la fuerza editora de «Atlántida». Así y por un lado, el estudio de C. Brafman ${ }^{35}$ se focaliza en la primera década de la colección, cuando entonces la influyente publicación se empeñaba en la promoción de la filantropía como un medio ideal y suficiente para sostener la convivencia entre los hombres bajo la representación de una desigualdad «natural». Al respecto, la autora identifica una temática solidaria (caridad, ahorro, gratitud, lealtad) de corte paternalista y moralizante destinada a prevenir o contener, en la sociedad y en las aulas, la conflictividad social ligada a las ideologías obreristas a la sazón arribadas con las oleadas inmigratorias. Por su parte, el libro de M. Varela ${ }^{36}$ examina el panteón de los «hombres ilustres» y su tratamiento escolar, comparando el patrón editorial y los «héroes» presentes en los libros de lectura durante las primeras décadas del S. Xx. Varios años después, «Billiken» estará nuevamente bajo la lupa con el trabajo de P. Guitelman pero ya sobre los años del terrorismo de Estado en Argentina

34 Al texto citado se agregan: La escuela en la historia argentina. Buenos Aires, Edhasa, 2009; El papel de la educación en la invención de lo social (o de cómo la historia escolar transformó progresivamente lo social en la Argentina), Revista de Indias, Madrid, 53 (2013b), pp. 219238. https:// core.ac.uk/download/pdf/276246528.pdf ; Periódicos de escolares en la Argentina. Producciones pedagógicas de la escuela primaria entre 1900-1960, en Hernández DíAz, J. M. (Ed.), La prensa de los escolares y estudiantes: su contribución al patrimonio histórico educativo, 2015, pp. II5-I29; Lectores y lecturas de la prensa de los profesores en la Argentina, en Hernández Díaz, J. M. (Ed.), La prensa pedagógica de los profesores. Universidad de Salamanca, Ediciones Universidad de Salamanca, 20I8, pp. 85-ioo; Finocchio, S., Stagno, L. y BrugaletTA, F., Introducción: la prensa pedagógica como espacio de formación, definición e innovación, Archivos de Ciencias de la Educación, La Plata, io (20I6).

https://www.archivosdeciencias.fahce.unlp.edu.ar/article/view/Archivoseoo2.

35 Brafman C., Billiken. Poder y consenso en la educación argentina (1919-1930), Todo es Historia, Buenos Aires, 4I (1992).

${ }^{36}$ Varela, M., Los hombres ilustres de Billiken. Héroes en los medios y en las escuelas, Buenos Aires, Colihue, 1994. 
(1976-1983 $)^{37}$, integrado a la notable obra de C. Kaufmann sobre Dictadura y Educación ${ }^{38}$. Justamente, la autora mencionada ofrece algunas descripciones que aquí nos sirven para explicar por qué, en un acotado universo de antecedentes, la revista se reitera en los estudios; a saber, «(...) adquiere valor documental debido a su alcance y difusión editorial que le permitió tocar picos elevadísimos de tirada llegando a ocupar un lugar central en la cultura argentina»39.

El tercer trabajo que nace en los años 90 pertenece a S. Gvirtz ${ }^{40}$ titulado «Estrategia de la escuela nueva a través de la revista La Obra y sus propuestas didácticas». Como se deduce, el capítulo se enmarca en una investigación más amplia y centrada en el escolanovismo, describiendo contrapuntos con el territorio brasileño. Ciertamente, la extensa colección resulta un aventajado soporte material para adentrarse en los orígenes y etapas de la versión local de la escuela activa, desde su aparición en I92I y reimprimiéndose hasta el presente de forma ininterrumpida, a excepción del año 1977. Dado el significativo interés por este objeto de estudio en Argentina, queda claro por qué se trata de una de las revistas más consultadas en la historiografía en general y en lo particular de lo que ahora se nombra como prensa pedagógica. Precisamente, a posteriori se suman los estudios de G. Ferreyra, G. Andrade y D. Revach. La primera autora compulsa la revista con otro «peso pesado» de la agenda temática nacional: la educación durante los primeros gobiernos peronistas (I946-1955) a los efectos de observar «(...) hasta qué punto y de qué manera se regularon las directivas pedagógicas desde i95o hasta $1955^{»^{4}}{ }^{\mathrm{r}}$. Con ello, se revisita el adoctrinamiento político-partidario siguiendo las estrategias editoriales según la selección y organización de los temas del currículum oficial, especialmente preparados para maestras y profesores. El segundo artículo se ubica en el período de la última dictadura; aquí se comprende que «La

37 Guitelman, P. Educar y entretener. La revista Billiken en los años de Dictadura, en KaufMANn, C. (Dir.) Dictadura y Educación. Tomo 3: Los textos escolares en la historia argentina reciente, Salamanca, FahrenHouse, pp. 299-328, $2018 \mathrm{~b}$.

${ }_{38}$ Dado que las primeras ediciones publicadas en Argentina se hallan agotadas, se sugiere ver las reediciones en línea a cargo FahrenHouse (Salamanca); a saber: Kaufmann, C. (Dir.). Dictadura y Educación. Tomo I: Universidad y Grupos Académicos Argentinos (1976-1983), Salamanca, FahrenHouse, 20I7; https://www.fahrenhouse.com/omp/index.php/fh/catalog/book/25; Dictadura y Educación. Tomo 2: Depuraciones y vigilancia en las universidades nacionales argentinas, Salamanca: FahrenHouse, 20I8a; https://www.fahrenhouse.com/omp/index.php/fh/catalog/book/27; Dictadura y Educación. Tomo 3: Los textos escolares en la historia argentina reciente, Salamanca, FahrenHouse, 2018b. https://fahrenhouse.com/blog/2018/o7/dictadura-y-educacion-tomo-3-los-textos-escolares-en-la-historia-argentina-reciente/

39 En edición original: Kaufmann, C. (Dir.) Dictadura y Educación. Tomo 3: Los textos escolares en la historia argentina reciente, Buenos Aires, Miño y Dávila, 2006, p. I9.

$4^{\circ}$ GvirTz, S. Estrategia de la escuela nueva a través de la revista La Obra y sus propuestas didácticas, en GvirTz, S. (Comp.) Escuela nueva en la Argentina y Brasil, Buenos Aires, Miño y Dávila, 1996.

${ }^{41}$ Ferreyra, G., La revista La Obra y la política educativa peronista, I950-I955. XIV Jornadas Interescuelas/Departamentos de Historia, Departamento de Historia de la Facultad de Filosofía y Letras, Universidad Nacional de Cuyo, Mendoza, 2013, p. 5. http://cdsa.aacademica.org/ooooIO/II54.pdf 
Obra» es «(...) un compendio de escrituras docentes que ponen de manifiesto sus propuestas de enseñanza en un contexto represivo» ${ }^{42}$. Siguiendo a Gonçalves Vidal (2005), la autora sostiene que la fuente le permite visibilizar las prácticas cotidianas bajo el terror de Estado, revelando una serie de tácticas ensayadas para resistir y/o apropiar las directivas autoritarias. En este caso, el estudio se fortalece de los importantes avances académicos en torno del pasado cercano; bien puede decirse: en él se reúnen lo incipiente de la prensa pedagógica y lo consolidado del campo de la Historia Reciente e Historia Reciente de la Educación Argentina.

Por su parte, el artículo de D. Revach ${ }^{43}$ resulta una pieza singular por lo curioso de leer un erudito estudio de historia educativa argentina en idioma portugués, dado la procedencia académica y profesional del autor (Universidad Federal de São Paulo). Fuera de ello, importa señalar que, como en el escrito anterior, el análisis atraviesa los convulsionados años '7o pero virando hacia las reconfiguraciones de la cultura docente por vía de editoriales y notas específicas. Esta variante permite descentralizar la mirada del componente represivo y abrir el panorama en otras dimensiones que vertiginosamente se aceleran desde finales de los '6o y hasta bien entrados los años '80; entre otras: el sesgo tecnocrático de una fallida reforma lanzada por la «Revolución Argentina» (1966-1973), las diversas valoraciones del magisterio y sus luchas gremiales, las rupturas y continuidades durante la transición democrática y el retorno o emergencia (según las hipótesis que se consideren) del constructivismo como discurso y propuesta pedagógica centrado en la figura de J. Piaget. Este trabajo, es un buen ejemplo de la riqueza, bien aprovechada, de la prensa pedagógica.

En virtud de su naturaleza gubernamental y registro temporal, las revistas «Anales de la Educación Común» (En adelante: «Anales») y «El Monitor de la Educación Común» (En adelante: «El Monitor»), constituyen una extraordinaria cantera empírica y de reflexión teórica ${ }^{44}$. Sin embargo, se cuenta con pocos trabajos que las aborden como objetos exclusivos, tal y como el artículo de C.

${ }^{42}$ Andrade, G. Prensa educativa e innovación pedagógica en tiempos de dictadura, Archivos de Ciencias de la Educación, La Plata, ıo (2016), p. 5.

https://www.archivosdeciencias.fahce.unlp.edu.ar/article/view/Archivoseoos

${ }^{43}$ Revach, D. La reconfiguración de la cultura docente en la revista argentina La Obra (1970-1980). En Cadernos de História da Educação, Uberlândia, I8 (2019), pp. 478-502. https://doi. org/Io.I4393/che-vi8n2-2019-I2.

${ }_{44}$ Siguiendo a Finocchio, cabe apuntar que «Anales» fue creada en I858 por D. F. Sarmiento, a la sazón Jefe de Departamento de Escuelas de la Provincia de Buenos Aires. En I865 quedó bajo la dirección de su amiga: la ilustre pedagoga Juana Manso hasta 1875. Ya siendo el órgano oficial de la flamante Dirección General de Escuelas en 1876, tuvo diferentes épocas: hasta I88I fue publicada con el nombre «La Educación Común en la Provincia de Buenos Aires»; entre I88I-I893 se denominó «Revista de Educación» y desde 1895 hasta 1916 fue el «oletín de Enseñanza y Administración Escolar». Por su parte, el «Monitor» se imprimió por primera vez en I88I difundiendo el quehacer del Consejo Nacional de Educación. Se diferencia de «Anales» respecto de su lectorado, pues no estuvo destinado a un público en general sino a inspectores y visitadores escolares al ritmo de la estricta agenda estatal. Op. cit. FinOcCHIO, S., La escuela en la historia, 2009. 
Bracchi ${ }^{45}$ en cuyo título se cifran claramente los propósitos del escrito: «Un recorrido histórico: desde los inicios hasta nuestros días. Acerca de la emblemática publicación bonaerense y argentina». De sus páginas vale subrayar la identificación y discriminación de otras «nuevas etapas» que se suman a las usualmente contempladas, producto de los escenarios políticos por los que discurrió o dado un conjunto de actores que imprimieron sus huellas editoriales. La autora traza entonces un panorama general pero también particular que merita la consideración de futuros estudios sobre dicho material. No obstante, ello no sucede en la ilustrada pesquisa de A. Bisso sobre los «(...) usos del pasado en los discursos y prácticas escolares, a partir de la lectura de la Revista de Educación (...) entre los años 1936 y 1940 durante el gobierno bonaerense de Manuel Fresco» ${ }^{46}$. De todas formas, un intercambio tácito se pone en juego cuando presenta una visión que escapa a la herencia historiográfica «simple y monolítica» en el doble plano de la revista y el periodo. La axiomática lógica «normalizadora» se descompone (y desordena) en algunos matices, en tanto «lo político» se inscribe como experiencia individual y colectiva. Para tal (logrado) objetivo, la prensa pedagógica cumple su promesa heurística.

Casi sobre el mismo período, «Anales» también será examinada en otro asunto o ya línea de indagación que ha cobrado fuerza en los últimos años. Nos referimos a los estudios sobre la educación del cuerpo y sus múltiples dimensiones político-ideológicas, pedagógicas, subjetivas, estéticas y sanitarias. Particularmente, E. Galak ${ }^{47}$ bucea en las páginas de las décadas del '20, '30 y '40, capturando los discursos eugenésicos y comparándolos con el escenario brasilero en todo lo que, al respecto, puede ofrecer su par «Revista do Ensino» de Minas Gerais. Antes de irnos de esta temática, registramos el libro coordinado por P. Scharagrodsky (notable estudioso del área). Publicado en el año 2008, incluye un trabajo de A. Aisenstein sobre las «Tensiones en el discurso de la educación física». Sin vacilaciones, se explicita que las definiciones halladas se examinarán en la «prensa pedagógica nacional», específicamente, en la «Revista de la Educación Física» (1909-1936) y en otra llamada «Fortitudo» (1921-1922), ambas de la provincia Buenos Aires ${ }^{4}$.

45 Bracchi, C., Anales de la educación común. Cuando la historia se hizo revista, Revista Anales de la Educación Común. Tercer Siglo, Buenos Aires, DGCyE de la Provincia de Buenos Aires, 2005 .

46 Bisso, A. La Revista Educación bonaerense durante el período de gobierno de Manuel A. Fresco (I936-1940): acerca de los «usos del pasado» en los discursos y las prácticas escolares, Clío y Asociados, UNL, Santa Fe, I5 (20II), p. I. http://www.clio.fahce.unlp.edu.ar/article/view/clionısao3

47 GalaK, E. Fortalecer los músculos para mejorar la raza. Discursos eugenésicos sobre educación del cuerpo en revistas pedagógicas de Argentina y Brasil (1920-1940), Sociohistórica, La Plata, 44 (2019). https://doi.org/I0.24215/18521606eo85.

${ }_{48}$ Aisenstein, A., Tensiones en el discurso de la educación física: definiciones en la prensa pedagógica, Argentina, I900-1940, en SCHARAGRODSKY, P., Gobernar es ejercitar: fragmentos históricos de la educación física en Iberoamérica, Buenos Aires, Prometeo Libros, 2008, pp. 65-74. 
Volviendo a «Anales», se sigue el trabajo de J. Gondra y C. Suasnábar; un estudio comparado entre Argentina, Brasil y EEUU triangulado por la revista rioplatense durante las direcciones de Sarmiento-Manso (I858-I873), la renombrada «The American Journal of Education» (1855-188I) de EEUU y «A Escola» (I877I878) de Brasil. Muchos párrafos podrían ocuparnos aquí en elogiosos comentarios, tanto por la aguda lectura que decanta de cada caso para explicar sus configuraciones y rasgos, como por la capacidad reflexiva para «elevar» el plano hacia una textura integral e integrada, logrando su cometido: «(...) demostrar cómo estos dispositivos conectan redes de poder y conocimiento articulado a formas de gobierno de la población y de los profesores, así como con los mecanismos de legitimación de modelos pedagógicos racionales y, con ellos, los proyectos comprometidos con formas de vida «modernas y civilizadas» ${ }^{49}$. También subrayamos el capítulo de M. Southwell (2018) ${ }^{5 \circ}$, y con éste, a la obra en su conjunto sumando autores de Brasil, Portugal, Uruguay y Canadá. Como se ha dicho a lo largo de este artículo, los organizadores que la presentan señalan que la prensa pedagógica permite revisar viejos temas y/o labrar nuevos horizontes, problemas y enfoques, significados - en este caso - en un trama de lo «trasnacional» que antes denominamos «comunidad académica internacional».

En cuanto a «El Monitor», se incluye aquí la investigación de F. Fiorucci focalizada en «Las representaciones del magisterio» entre las décadas de 1900 y 1930 ${ }^{\text {sI. }}$ Pero aquí, antes que su estricto contenido conviene observar un aspecto más amplio. En principio, entendemos que no resulta casual que este trabajo se halle incorporado en una obra colectiva dedicada a las revistas culturales desde la perspectiva de la teoría y crítica literaria, de gran vitalidad en Argentina. La presencia de este capítulo solitario en un conjunto de propuestas afincadas en los estudios culturales, es una suerte de invitación de una «jurisdicción» disciplinar a otra, articulada por el relieve de una materialidad en común. Después de todo, el mundo de las revistas culturales ha estrechado con el campo educativo algo más que un dispositivo. Han compartido pues discursos, actores y agentes que, en determinados contextos históricos, pivotearon estos espacios sin mayores fricciones. Cierto es que, el propio edificio simbólico del sistema educativo argentino, se construyó con las plumas de pedagogos literatos y de literatos pedagogos,

49 Gondra, J. y SuAsnábar, J., Revistas pedagógicas y gobierno (intenso, sutil y prolongado) del profesorado. Estados Unidos, Argentina y Brasil (I855-I88I), Historia de la Educación. Anuario SAHE, Buenos Aires, I7 (2016), p. Io. http://ppct.caicyt.gov.ar/index.php/anuario/article/view/6675/ $\mathrm{pdf}$

Southwell, M., La revista Anales de la Educación Común (Buenos Aires, I920-1940): formación estética y sensible en el trabajo docente, En Bortoleto Nery, A. C. y Gondra, J. (Org.), Imprensa pedagógica na ibero-américa: local, nacional e trasnacional, Sao Paulo, Alameda, pp. 137I52, 2018.

${ }_{51}$ FIORUCCI, F. Las representaciones del magisterio en la prensa oficial: El Monitor de la Educación, 1900-1930, en Delgado, V., Mailhe A., y Rogers, G. (Coords.) Tramas impresas: Publicaciones periódicas argentinas (XIX-XX), La Plata, Universidad Nacional de La Plata, 20I4, pp. 243-257. 
frecuentemente integrados a círculos y redes que confluían e influían en el aparato estatal, rubricando normativas y reformas trascendentales.

Acaso por lo dicho, también podemos encontrar artículos que van en la dirección opuesta, tal y como el trabajo de S. Pattin titulado «La educación entre la familia, el Estado y la Iglesia. Criterio y Combate, la Argentina plural y la nación católica» (1955-1957)». El artículo revisa los distintos proyectos políticos-religiosos del catolicismo durante el periodo desarrollista. En tanto el autor explicita su filiación en «(...) la consolidada historiografía de revistas y diarios» $\aleph^{2}$, el paper se publica en el órgano de difusión de la Sociedad Argentina de Historia de la Educación (SAHE). A riesgo de excedernos en estos señalamientos interdisciplinares, finalmente agregamos que, en tanto los estudios culturales y de crítica literaria se hallan afianzados con el impulso de las últimas décadas, o recogiendo una notable tradición desde mediados de la década del '6o (Prieto, Sarlo, Gramuglio, Sábato, entre tantos otros), ello no es la realidad de la prensa pedagógica. Por el contrario, el panorama se presenta escaso, fragmentado e inconexo.

Lo antedicho intenta ser otra caracterización del ámbito nacional y no así una valoración de las indagaciones de forma individual. Por el contrario, muchas de ellas nutren nuestras perspectivas dejándonos un buen puñado de lecciones sobre la forma de abordar los impresos. Por esto mismo, corresponde reseñar ejemplares que siquiera entran en el radar de los contados repertorios (parciales) elaborados en Argentina ${ }^{\varsigma 3}$.

Así, puede mencionarse a L. Rodríguez ${ }^{54} \mathrm{y}$ su análisis sobre la revista «Mikael» (1973-1984) ligada al nacionalismo católico preconciliar, en rigor ya pesquisada meritoriamente por D. Doval en el primer tomo de «Dictadura y Educación» dirigido por Kaufmann`s. En este mismo libro, también puede leerse la interesante labor de C. Suasnábar ${ }^{56}$ sobre la revista «Perspectiva Universitaria», asumiendo una dimensión poco explorada por entonces: «las voces disidentes» durante la férrea censura estatal desde 1976; un abordaje que, sin ánimos de heroicidad, advierte las hendijas de resistencias en dicho contexto.

52 Pattin, S. La educación entre la familia, el Estado y la Iglesia. Criterio y Combate, la Argentina plural y la nación católica (1955-1957)", Anuario de Historia de la Educación, Buenos Aires, I8 (2017), pp 97-IIO, p. 88. http://ppct.caicyt.gov.ar/index.php/anuario/article/view/9918/pdf

53 Palamidessi M., Las revistas académicas del campo de la educación (Argentina, 1990-2002), La Plata, Departamento de Ciencias de la Educación, 2007; Finocchio, S., op. Cit, 2009. https://www. archivosdeciencias.fahce.unlp.edu.ar/article/view/ARCHvornorao6

54 Rodríguez, L., El «marxismo» y la universidad en la revista Mikael (1973-1984), Ciencia, Docencia y Tecnología, Paraná, 45 (2012), pp. I47-162.

http://www.memoria.fahce.unlp.edu.ar/art_revistas/pr.9187/pr.9187.pdf

"Doval, D., Una escuela de pensamiento. Universidad y dictadura: un estilo de vida misional, en Kaufmann, C. (Dir.), Dictadura y Educación. Tomo I: Universidad y Grupos Académicos Argentinos (1976-1983), Salamanca, FahrenHouse, 2017, pp. I25-I48.

${ }_{56}$ Suasnábar, C., Revista Perspectiva Universitaria. Voces disidentes en dictadura, en KaUFmann, C. (Dir.), Dictadura y Educación. Tomo I: Universidad y Grupos Académicos Argentinos (1976-1983), Salamanca, FahrenHouse, 2017, pp. 179-212. 
Más cercano en el tiempo, damos con la publicación de J. Méndez y N. Vuksini sobre el periódico «Educación Popular» de Buenos Aires. Si bien no se detalla la temporalidad de su vida editorial de «(..) tirada irregular (...) y una distribución de tipo 'casera' con suscripciones y distribución 'de mano en mano'», el examen se afinca en «(...) un conjunto de ellos [ejemplares] editados entre los años 1963 y I966»\$7. Esta sola mención, y el hecho de acceder a aquellos números por la colaboración de un «importante educador» que los conservó aun durante el régimen militar, resultan indicadores de largos problemas en las políticas de archivo en Argentina; un asunto que ahora excede estas páginas pero que impacta decididamente dentro y fuera del campo bajo análisis.

Cabe citar también el trabajo de M. Fernández y E. Welti $i^{8}$ basado en la particular colección de la revista "Quid Novi?», publicada entre 1932 y 1934 por las Asociaciones de Padres y de Ex-alumnas de la Escuela Normal Superior $\mathrm{N}^{\circ} 2$ de Rosario. En los peculiares rasgos de aquella institución normalista y el proyecto pedagógico dirigido por la escolanovista Bernardina Dabat, se explica la articulación entre arte, cultura y pedagogía, bien aprovechada por las autoras en su descripción general y en la laboriosa traducción de objetos modernizadores, gestos estéticos e iniciativas intelectuales que caracterizaron sus páginas.

Hasta aquí entonces, el total de la bibliografía citada muestra dónde se hallan las preferencias temporales según los objetos recortados:

GrÁfICO V: Distribución de los periodos en estudios sobre prensa pedagógica en Argentina.

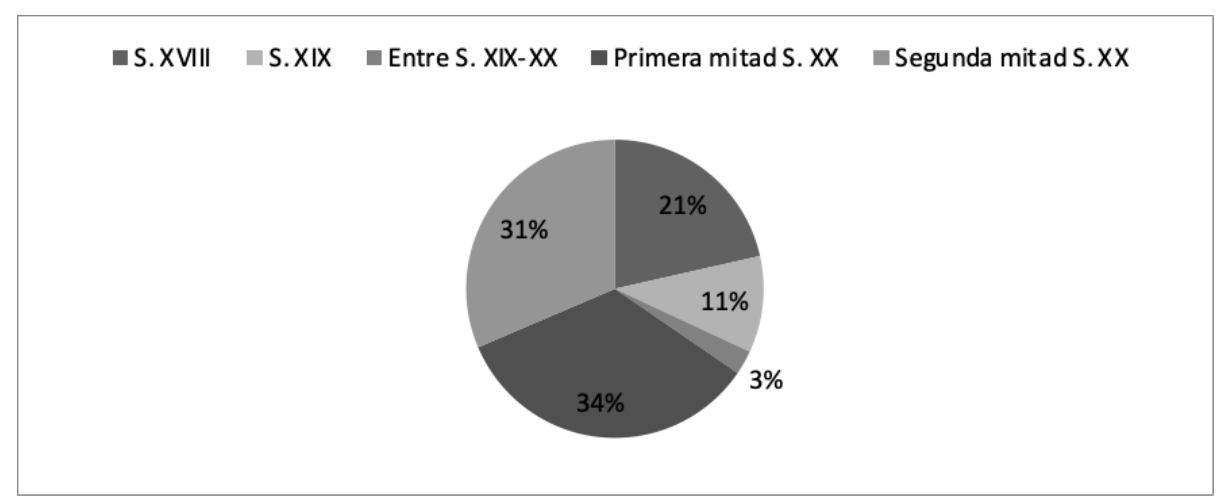

Fuente: elaboración propia.

57 MéndeZ, J. y Vuksinic, N., La problemática educativa argentina de la década del ‘6o: un análisis del periódico Educación Popular, Temas em Educação, Paraíba, 24 (2015), p. 6o. http://hdl. handle.net/In336/58968

${ }_{58}$ Fernández, M. y Welti, E., Más allá de lo escolar: definiciones pedagógicas y discurso visual. Análisis de la revista Quid Novi? (Rosario, 1932 - 1934), en Archivos de Ciencias de la Educación, La Plata, IO, 20I6. https://www.archivosdeciencias.fahce.unlp.edu.ar/article/view/Archivoseoo4 
Como puede verse, el S. Xx concentra la mayoría de los estudios (65\%) focalizados en las décadas del '20 y '30, por un lado, y los convulsionados '60 y' 70 , por el otro; una característica que no se aleja demasiado de las tendencias de la historiografía general. El contrapunto se halla acaso en las escasas publicaciones sobre la educación durante los primeros gobiernos peronistas, cuando en verdad es una temática harto explorada desde diferentes tópicos y dimensiones. Para ello, los investigadores han recurrido a estos materiales; más aún, el periodo ha sido reiteradamente analizado con este tipo de fuentes siendo un elemento central del adoctrinamiento político, dentro y fuera de las aulas. Así, desde los textos escolares de lectura obligatoria como «La razón de mi vida» de Eva Duarte (195I) o «El hada buena» (1954), a la liturgia de las variadas revistas militantes que circularon entre la masa obrera, jóvenes y estudiantes, como aquella creada por la Unión de Estudiantes Secundarios (UES) o la popular «Mundo peronista», ocupan largas páginas de la historia educativa. Sin embargo, ese mismo rasgo doctrinario, las tensiones de los liderazgos políticos y/o la generalidad de las importantes políticas desarrolladas, son finalmente los objetos que realmente capturan la atención. Si de campos se trata, la oferta documental no se ha desplazado a la prensa pedagógica, sino antes a los estudios culturales ${ }^{9}$.

Finalmente, el gráfico incluye los trabajos de S. Finocchio antes reseñados como los principales antecedentes en tanto objeto y campo autónomo. Al respecto, nos centramos en el libro editado en el año 2009 y en el artículo titulado «El papel de la educación en la invención de lo social (o de cómo la historia escolar transformó progresivamente lo social en la Argentina)» publicado en 2013. A nuestro entender, en ellos se verifican dos elementos auspiciosos para un avance cualitativo de esta línea de indagación; esto es: un análisis que atiende a la singularidad de los ejemplares identificados, y el esfuerzo por integrar la dispersión que se genera.

Así, «La escuela en la historia» (2009) ${ }^{60}$ se traduce en el primer catálogo nacional $^{6 t}$ conformado por 350 publicaciones que circularon entre los siglos XIX y $\mathrm{XX}$, sistematizadas en seis tipologías; a saber: a) publicaciones sobre el sistema educativo y las instituciones escolares; b) publicaciones para docentes; c) publicaciones para un tipo particular de educación; d) periódicos destinados al apoyo

59 Solo para ilustrar, el libro compilado por Claudio Panella y Guillermo Korn (20I4) Ideas y debates para la nueva Argentina: revistas culturales y políticas del peronismo, presenta dos capítulos específicos. Uno dedicado a la revista de la UES (1954-1955) escrito por A. Cammarota, y otro a cargo de M. Farías sobre la publicación «Universidad» entre 1943-1955.

$60 \mathrm{La}$ ausencia de los términos «prensa pedagógica» $\mathrm{o}$ «revistas educativas» se significan en un aspecto que, dado los objetivos de este artículo, han quedado en un segundo plano. Nos referimos al declarado (y logrado) propósito de revisar algunas representaciones cristalizadas de la historia educativa en la larga duración, matizando un conjunto de discursos monolíticos y pasados míticos o ya estereotipados.

${ }_{61}$ Si bien la publicación de M. Palamidessi es anterior (2007), el universo se recorta a la descripción y primeros análisis de revistas académicas argentinas especializadas en educación durante la década de 1990. 
y la inclusión; e) revistas de educación no formal y f) publicaciones del campo de la pedagogía ${ }^{62}$. Por su parte, el estudio del año 2013 deja ver una fecunda operación historiográfica que articula la emergencia de una serie de importantes revistas ${ }^{63}$, recostadas sobre los cambiantes escenarios políticos, pedagógicos y epistemológicos desde la segunda mitad del S. XIX hasta los años '9o del Xx. El texto teje los hilos del pasado dispuestos por agentes estatales, actores clave «en movimiento» (con sus trayectorias, itinerarios y asociaciones intelectuales), por idearios del poder y proyectos de nación en cada época. Recupera, en cada caso, las respectivas dosis de moralización, democratización y autoritarismo; la contención, pero también el desborde, de la dimensión ideológica en las páginas prensadas; las corrientes de pensamiento y la irrupción de sus discursos; los ensayos, las experiencias y métodos importados aunque siempre resinificados en el terruño; los contenidos didactizados; la asistencia prescriptas o sugeridas para impregnar las aulas de rituales y gestos que edificaron la cultura escolar, su materialidad cotidiana y la «parafernalia de artefactos».

Visto así, puede que los estudios en prensa pedagógica realizados en Argentina sean insuficientes y se hallen dispersos, pero la exploración ha comenzado.

\section{Reflexiones finales}

El presente trabajo partió de dos asuntos centrales y articulados: la idea de que la prensa pedagógica en Argentina es un área vacante de conocimiento, y la empiria de un potente archivo depositado en la Biblioteca Vigil de Rosario, a la espera de un tratamiento historiográfico. En otras palabras: la proposición teórica de un «tesoro inexplorado» y la manifestación objetiva de un «tesoro desmantelado»; uno y otro, unidos por el mismo horizonte de expectativas: la potencia de futuras indagaciones. Para ello, nos propusimos identificar, describir y analizar la productividad del campo en el ámbito nacional e internacional, siguiendo los logros y desafíos de una comunidad académica consolidada. Ciertamente, el estado de la cuestión cumple la función erudita de enmarcar y reafirmar el valor patrimonial de las publicaciones periódicas nacidas del programa de canje de la UNESCO, sobreviviendo al genocidio cultural. Vale decir, la investigación en curso y los

${ }_{62}$ En sintonía, el estudio del año 2018 presenta una serie de clasificaciones sobre las prácticas de lecturas del magisterio argentino. A sabiendas de la enorme complejidad que siempre reviste esta trama en términos de percepciones, sensaciones y emociones, la autora avanza en tal complejo terreno organizándolas teóricamente en: la lectura «eficaz», las lecturas «clandestinas», la lectura «solitaria», la lectura «gustosa», la lectura «cómplice», la lectura «militante», la lectura «crítica» y la lectura «femenina».

${ }_{3}$ Anales de la Educación Común; La Nueva Escuela; La Escuela Positiva; La Educación; Revista de Educación; El Monitor de la Educación; Billiken; Revista de Pedagogía; Boletín del Instituto de Pedagogía; La Obra; Cátedra y Vida; La Educación Católica; Revista del Instituto de Investigaciones Educativas (IIE); Escuela para Padres; Maestra Jardinera; Maestra del Primer Ciclo; Maestra del Segundo Ciclo; La revista del Tercer Ciclo; La Revista del Polimodal y Magazine teacher's. 
estudios particulares que en adelante surjan, pueden considerarse una revalorización académica del archivo, dado que - sin desmemorias ni silencios sobre su pasado reciente - lo empuja hacia el futuro para dejar de ser un «depósito sin sentido» ${ }^{64}$.

Lo antedicho se desprende de todo lo leído y analizado en la literatura, especialmente en el ámbito internacional, cuyos resultados se inscriben en un campo específico que ha mostrado un notable crecimiento en los últimos años. Bien puede decirse, se trata de una línea de investigación que, en tanto define con claridad el objeto material, se muestra más vaga en la porosidad de los contornos del campo, desplegando «(...) un espacio pedagógico inmenso» ${ }^{65}$. Por esto mismo, algunos autores insisten en el desafío de construir nuevos repertorios analíticos de fácil identificación y localización, según sus múltiples géneros y modalidades (prensa de la cultura escolar, institucional, sistémica, no formal, estatal, eclesial, científica, etc.), y ofreciendo una orientación panorámica tal, que permita un avance estratégico. En sintonía, detectamos alguna urgencia por integrar la dispersión del antedicho crecimiento; sortear el estadio de un acumulado de casos e ir hacia un ordenamiento referencial y dialogado de los antecedentes producidos. En este aspecto, muchos investigadores dejan propuestas sintéticas sin por ello borrar los matices que anidan entre tanta heterogeneidad.

Si de logros se trata, pocas dudas quedan sobre la utilidad académica de los impresos. Los centenares de libros, capítulos y artículos provenientes de gran parte de Iberoamérica y otras regiones de Europa, son prueba de su vitalidad. En este aspecto, los estudios saturan el mismo augurio: la posibilidad genuina de explorar viejas y novedosas temáticas de la historia educativa: desde las políticas gubernamentales a la micropolítica de las instituciones y la cultura escolar, dinamizadas por las estructuras y las coyunturas, por los objetos, procesos y normativas que se escurren entre los meandros del sistema o ya desbordándolo en acciones, pensamientos y emociones.

Los desafíos y potencialidades descriptos, aplican a la Argentina contando con este tipo de prensa desde la segunda mitad del siglo XIX, emergiendo como un instrumento gravitante para la conformación y consolidación de su aparato educativo. Agenciada por el Estado, por diversas asociaciones del magisterio y/o por las tempranas experiencias del periodismo escolar, fue un engranaje clave para las décadas de modernización estatal y construcción de las identidades nacionales. De igual forma, permite el examen de las marchas y contramarchas de las principales corrientes pedagógicas, pues ellas también tuvieron «prensa»; desde la ilustración, el cientificismo y el positivismo, a los espiritualismos; desde las imprentas oficiales o clandestinas de anarquistas, socialistas y comunistas, a la maquinaria de los gobiernos peronistas; desde las confluencias teóricas de la etapa desarrollista, al estructuralismo; de los constructivismos a la experiencia neoliberal con su poderío editorial.

${ }_{64}$ Nazar, M., El hilo de Ariadna, Políticas de la Memoria, 6/7 (2006), pp. 2I2-2I8.

65 Op. cit., Hernández Díaz, J. M., Prensa pedagógica y patrimonio..., 2013, p. I6. 
En suma, por una y otra vía se comprendió la advertencia de Finocchio: nuestra prensa pedagógica ha sido medianamente aprovechada en su talante heurístico, pero inexplorada en su potencialidad hermenéutica; como campo y objeto autónomo. De todas formas, también consideramos que el escenario en cuestión por lejos se traduce en un vacío historiográfico, reconociendo toda una tradición local que hurgó en estos materiales con diversos propósitos disciplinares, mostrando incluso un punto de fuga hacia los estudios literarios y culturales. En tal particular universo, identificamos un conjunto de referencias que ubicamos en una zona o «literatura gris»; una porción significativa de antecedentes que, sin autodenominarse "prensa pedagógica», finalmente lo es. 